January 2004

\title{
Higher IL-10 levels are associated with less effective clearance of Plasmodium falciparum parasites
}

\author{
E. Hugosson
}

Karolinska Institutet

S.M. Montgomery

Stockholm University

Zul Premji

Aga Khan University, zul.premji@aku.edu

M. Troye-Blomberg

Stockholm University

A. Bjorkman

Karolinska Institutet

Follow this and additional works at: http://ecommons.aku.edu/eastafrica_fhs_mc_pathol

Part of the Pathology Commons

\section{Recommended Citation}

Hugosson, E., Montgomery, S., Premji, Z., Troye-Blomberg, M., Bjorkman, A. (2004). Higher IL-10 levels are associated with less effective clearance of Plasmodium falciparum parasites. Parasite Immunology, 26(3), 111-117.

Available at: http://ecommons.aku.edu/eastafrica_fhs_mc_pathol/80 


\title{
Higher IL-10 levels are associated with less effective clearance of Plasmodium falciparum parasites
}

\author{
E. HUGOSSON, ${ }^{1,2}$ S. M. MONTGOMERY, ${ }^{3,4}$ Z. PREMJI, ${ }^{5}$ M. TROYE-BLOMBERG ${ }^{2}$ \& A. BJÖRKMAN ${ }^{1}$
}

${ }^{1}$ Malaria Research Unit, Division of Infectious Diseases, Department of Medicine, Karolinska Hospital, Karolinska Institutet, Stockholm, Sweden, ${ }^{2}$ Department of Immunology, Stockholm University, Stockholm, Sweden, ${ }^{3}$ Clinical Epidemiology Unit, Department of Medicine, Karolinska Hospital, Karolinska Institutet, Stockholm, Sweden, ${ }^{4}$ Kliniskt forskningscentrum, Universitetssjukhuset, Örebro, Sweden, and ${ }^{5}$ Department of Parasitology/Medical Entomology, Muhimbili University College of Health Sciences, Dar es Salaam, United Republic of Tanzania

\section{ABSTRACT}

The implications of high levels of the immune regulatory cytokine IL-10 in Plasmodium falciparum malaria are unclear. IL-10 may down-regulate pro-inflammatory responses and also exacerbate disease by inhibiting anti-parasitic immune functions. To study possible inhibiting effects on parasite clearance, IL-10 plasma levels were determined in 104 Tanzanian children, 1 to 4 years old, with acute uncomplicated $\mathrm{P}$. falciparum malaria, and analysed for association with parasite densities during 3 days of anti-malarial treatment. Higher baseline IL-10 plasma levels were associated with statistically significantly higher parasite densities after 24, 48 and 72 h of treatment. These associations could not be explained by differences in initial parasitaemia, temperature, age, sex or type of treatment. Induction of high IL-10 production might be a direct or indirect mechanism whereby the parasite evades the immune response.

Keywords Plasmodium falciparum, malaria, IL-10, parasitaemia, parasite density

Correspondence: E. Hugosson, Malaria Research Unit, Division of Infectious Diseases, Karolinska University Hospital, 17176 Stockholm, Sweden (e-mail: ehugosson@hotmail.com). Accepted for publication: 8 March 2004

\section{INTRODUCTION}

Work on murine experimental malaria suggests that a non-lethal outcome of a malaria infection can, in part, be explained by the ability of the mice to mount an early proinflammatory response, defined by IL-12, IFN- $\gamma$ or TNF- $\alpha$ production $(1-3)$. TNF and IFN- $\gamma$ act synergistically to optimize nitric oxide $\left(\mathrm{NO}^{-}\right)$production, which is implicated as an important factor in parasite killing (4). However, overproduction of IFN- $\gamma$ and TNF- $\alpha$ predisposes to severe pathology (5-7), suggesting that the ability to regulate the pro-inflammatory responses is also crucial to survive the infection. IL-10 is an anti-inflammatory cytokine which is able to modulate immune responses to parasites in several ways, including by inhibiting the production of IFN- $\gamma$ and IL-12. The clinical importance of IL-10 as a modulator of the pro-inflammatory responses seen in human malaria is however, yet to be defined. A low IL-10/TNF- $\alpha$ ratio, rather than only high levels of TNF- $\alpha$, is associated with malarial anaemia (8-11). This suggests that anaemia might be promoted by high pro-inflammatory responses in the absence of appropriate levels of anti-inflammatory factors. In severe malaria, lower levels of plasma IL-12 and $\mathrm{NO}^{-}$combined with higher IL-10 levels suggest that anti-parasitic responses might be suppressed by high levels of anti-inflammatory responses, resulting in severe disease $(12,13)$.

The relationship between initial plasma levels of IL-10 and parasite densities, determined daily during 3 days of treatment, was studied in 104 children with acute uncomplicated Plasmodium falciparum malaria, with the hypothesis that IL-10 inhibits anti-parasitic immune responses. The Tanzanian children, aged between 1 and 4 years, were admitted to the hospital for a trial comparing four different anti-malaria treatment regimes. 


\section{METHODS}

\section{Study area and patients}

Data and samples in this work were obtained from patients included in a study designed to compare antipyretic, parasitological and immunological effects of four different antimalaria treatment regimes (14). The study was carried out in Kibaha District Hospital $40 \mathrm{~km}$ north-west of Dar es Salaam, Tanzania, an area holoendemic for malaria with largely perennial transmission of mainly P. falciparum. Children between 12 and 59 months of age attending the primary health care unit of the hospital, between 3 July and 20 August 1998, were included in the study if they fulfilled the inclusion criteria of uncomplicated mono-infection with P. falciparum (2000-250 000 parasites $/ \mu \mathrm{L}$, axillary temperature $37 \cdot 5-40 \cdot 0^{\circ} \mathrm{C}$ ). Children were not eligible for the study if they had severe malaria (as defined by altered level of consciousness, convulsions, prostration, circulatory shock or respiratory distress), hyperparasitaemia (> 250000 parasites/ $\mu \mathrm{L}$ ) or severe anaemia (haemoglobin level below $5 \cdot 0 \mathrm{~g} / \mathrm{dL}$ ). Children with signs of coexisting diseases were also excluded. The guardians of the children satisfying the inclusion criteria were asked for their informed consent for the children to be finally enrolled into the study. Ethical clearance has been obtained from the Ministry of Health, Tanzania and the Research Ethical committee of the Karolinska Institutet, Stockholm, Sweden. The patients were admitted to the hospital and treated with chloroquine phosphate alone (F Hoffman-La Roche, Basel, Switzerland) once daily for 3 days, sulfadoxine/pyrimethamine (SP) alone (F HoffmanLa Roche, Basel, Switzerland) single dose, or SP + chloroquine or SP + paracetamol.

\section{Sample collection}

All children remained in the ward for 3 days. Axillary body temperature was measured with a digital thermometer at attendance to the primary health care unit of the hospital and at the start of treatment (Time 0). Parasite species were assessed by Giemsa-stained thin blood smears at admission, and parasite densities by thick blood smears daily for 4 days. The parasite densities were estimated by counting asexual parasites per 200 leucocytes in the thick smear and expressed as number of parasites per $\mu \mathrm{L}$ of blood, assuming an average number of 8000 leucocytes per $\mu \mathrm{L}$ of blood. Blood samples for cytokine determination were collected on day 0 (before start of treatment), day 2 and day 3. The plasmas were immediately separated by centrifugation and stored at $-30^{\circ} \mathrm{C}$ during the time of the study (at the most 2 months) and thereafter stored at $-70^{\circ} \mathrm{C}$ until transferred on dry ice and stored at $-70^{\circ} \mathrm{C}$ until analysed in the year 2000 . Out of
169 patients who participated in the study for $72 \mathrm{~h}, 104$, equally distributed between the four treatment groups, were randomly selected for cytokine analyses.

\section{Cytokine determination}

Cytokine analyses were performed by a sandwich ELISA. Half-area ELISA plates (Corning Incorporated, Corning, NY, USA) were coated overnight at $4^{\circ} \mathrm{C}$ with $25 \mu \mathrm{L}(1 \mu \mathrm{g} / \mathrm{mL})$ catcher $\alpha$-IL-10 antibodies (9D7) (MABTECH, Stockholm, Sweden). Phosphate buffered saline (PBS) supplemented with $0 \cdot 05 \%$ bovine serum albumin was used for blocking (90 min, at RT) and for dilution of standards and plasma samples. To ensure specific binding, blocking mouse antibodies (1DIK) (MABTECH, Stockholm, Sweden) were applied to the plates ( $20 \mu \mathrm{g} / \mathrm{mL}$, final concentration) immediately before samples and standards and incubated overnight at $4{ }^{\circ} \mathrm{C}$. The samples from each patient were coded and distributed randomly in duplicates (diluted $1: 1$ ) in the plates. Bound cytokines were assayed using biotinylated $\alpha$-IL-10specific antibodies (12G8, $1 \mu \mathrm{g} / \mathrm{mL}, 25 \mu \mathrm{L} /$ well) (MABTECH, Stockholm, Sweden) for $2 \mathrm{~h}$ at $37^{\circ} \mathrm{C}$, followed by alkaline phosphatase (ALP)-conjugated streptavidin (MABTECH, Stockholm, Sweden) diluted $1: 1000$ and incubated (90 min, at RT). Phosphatase substrate (Sigma Diagnostics, St Louis, MO, USA) was applied and the optical density was read at $450 \mathrm{~nm}$. Cytokine concentrations were calculated from standard curves obtained by incubating serial dilutions of recombinant IL-10 (NIBSC, Hertfordshire, United Kingdom). The standard was aliquoted and stored at $-70^{\circ} \mathrm{C}$.

The lower limit of detection, $30 \mathrm{pg} / \mathrm{mL}$, was set according to the linear part of the standard curve and the background values of the buffer controls. The antibodies used for detection recognize both human and viral IL-10. TNF- $\alpha$ levels were detected with the same procedure at the same time with the antibodies Mab 1 and Mab 11 (Pharmingen, San Diego, CA, USA).

\section{Statistical analysis}

The statistical package Stata was used for data analysis. The associations of IL-10 levels (at time 0), with parasite densities at times 24, 48 and $72 \mathrm{~h}$, were assessed using ordered polytomous logistic regression. With this statistical method it is possible to study the association between IL-10 levels and parasite densities even with an increasing proportion of the individuals with no parasites. Parasitaemia at time 0 was $\log _{\mathrm{e}}(x+1)$ transformed, and because this measure was normally distributed, it was modelled as a continuous variable. This provided the finest grain adjustment possible in a conditional change model. By 'finest grain' we mean that adjustment for the baseline parasitaemia at zero hours uses 
the most precise measure possible and with greater precision than the subsequent measures of parasitaemia used as dependent variables. This will ensure that reported associations with parasitaemia are not artefacts of (perhaps subtle) differences at baseline parasitaemia. Models such as these are known as conditional change models because the dependent variable is conditioned on (adjusted for) an earlier measure of the same factor.

Parasite densities at 48 and $72 \mathrm{~h}$ were not normally distributed, even after log transformation. At all time points, the measures were therefore converted into ordinal categorical variables to allow for comparable analysis for all outcome times. Parasite densities were categorized into fifths of their distribution at $24 \mathrm{~h}$, with an additional category for those without any detected parasites. We used the distribution with the widest range of values (parasitaemia at $24 \mathrm{~h}$ ) to define the boundaries for our categories. If the distribution at any of the other time points (48 or $72 \mathrm{~h}$ ) had been used, the results would have been substantially similar but the measure would have been less sensitive. IL-10 and temperature were categorized into fifths of their distributions and age was modelled in separate years (1-5). Simultaneous mutual adjustment was made for: treatment, temperature at $0 \mathrm{~h}$, IL10 at $0 \mathrm{~h}$, parasite density at $0 \mathrm{~h}$, age and sex. All variables were modelled as series of binary dummies with the exception of parasite density at Time 0 . Interaction of IL-10 with treatment strategy was also tested. The interaction term was included in the models with adjustment for baseline parasitaemia and the other potentially confounding factors as well as the main effects (IL-10 level and treatment strategy).

\section{RESULTS}

\section{Data distribution}

Plasma levels of IL-10 were detectable in all 104 patients and categorized as shown in Table 1. The distribution of parasite densities at $24 \mathrm{~h}$ was categorized by division into fifths. The same cut-points for parasitaemia were used when categorizing the distribution at 48 and $72 \mathrm{~h}$ (Table 1), for continuity between the three sets of models.

\section{IL-10 levels at $0 \mathrm{~h}$ and subsequent parasite densities}

Tables 2-4 show odds ratios for parasite density associated with IL-10 level at time $0 \mathrm{~h}$. A higher odds ratio indicates a higher likelihood of greater parasite density in an IL-10 category compared with the reference.

Higher concentrations of IL-10 at time 0 were associated with subsequently higher parasite densities at 24, 48 and $72 \mathrm{~h}$ of treatment (Tables 2-4 and Figure 1) independently of
Table 1 Distribution of the measures in 104 Tanzanian children with $P$. falciparum

\begin{tabular}{|c|c|c|c|}
\hline Categories & $\begin{array}{l}\text { Number } \\
\text { of patients }\end{array}$ & Categories & $\begin{array}{l}\text { Number } \\
\text { of patients }\end{array}$ \\
\hline Parasitaemia 0 h & & IL-10 $0 \mathrm{~h}$ & \\
\hline 0 & 0 & $0-185.99$ & 21 \\
\hline $1-1152$ & 0 & $186-439 \cdot 99$ & 20 \\
\hline $1153-2835$ & 1 & $434-746 \cdot 99$ & 20 \\
\hline $2836-8103$ & 11 & $747-1699 \cdot 99$ & 22 \\
\hline $8104-22026$ & 24 & $1700-15280$ & 21 \\
\hline $22027-200000$ & 68 & Temperature 0 h & \\
\hline Parasitaemia 24 h & & $37 \cdot 4-37 \cdot 8$ & 19 \\
\hline 0 & 1 & $37 \cdot 9-38 \cdot 2$ & 24 \\
\hline $1-1152$ & 20 & $38 \cdot 3-38 \cdot 4$ & 16 \\
\hline $1153-2835$ & 20 & $38 \cdot 5-38 \cdot 7$ & 21 \\
\hline $2836-8103$ & 23 & $38 \cdot 8-40 \cdot 1$ & 24 \\
\hline $8104-22026$ & 20 & Treatment & \\
\hline $22027-200000$ & 20 & Chloroquine & 25 \\
\hline Parasitaemia $48 \mathrm{~h}$ & & SP & 26 \\
\hline 0 & 47 & $\mathrm{SP}+$ Chloroquine & 26 \\
\hline $1-1152$ & 38 & $\mathrm{SP}+$ Paracetamol & 27 \\
\hline $1153-2835$ & 5 & Age (months) & \\
\hline $2836-8103$ & 8 & 12 & 8 \\
\hline $8104-22026$ & 3 & $13-24$ & 37 \\
\hline $22027-200000$ & 3 & $25-36$ & 36 \\
\hline Parasitaemia $72 \mathrm{~h}$ & & $37-48$ & 17 \\
\hline 0 & 80 & $49-58$ & 6 \\
\hline $1-1152$ & 12 & Sex & \\
\hline $1153-2835$ & 9 & Male & 56 \\
\hline $2836-8103$ & 1 & Female & 48 \\
\hline $8104-22026$ & 2 & & \\
\hline $22027-200000$ & 0 & Total number & 104 \\
\hline
\end{tabular}

Parasite density (parasites $/ \mu \mathrm{L}$ ) was divided into fifths of its distribution at $24 \mathrm{~h}(24 \mathrm{~h})$ and the same division was used for all time points. IL-10 and temperature values are categorized according to plasma levels $(\mathrm{pg} / \mathrm{mL})$ or degrees Celsius $\left({ }^{\circ} \mathrm{C}\right)$ at time $0 \mathrm{~h}$. Each age category represents 1 year of age. $\mathrm{SP}=$ Sulfadoxine-Pyrimethamine.

initial parasitaemia. Since the patients were treated with four different treatment regimes, adjustment was consistently made for this factor. Categorical and continuous log-transformed measures of initial parasitaemia were compared, in the same model, for the strongest association with parasitaemia at 24, 48 and $72 \mathrm{~h}$. The continuous variable presented the finest-grain adjustment (data not shown) and was therefore used (in columns 2 and 3). In the final model (column 3), adjustments were made for several potential confounding factors: treatment, initial parasitaemia, temperature, age and sex. At $24 \mathrm{~h}$ (Table 2), the association increased between each succeeding category of IL-10 and was statistically significant for the categories with the two highest IL-10 levels compared to the lowest. At 48 and 72 h, the levels went up until the second highest category of IL-10 and then reached a plateau (Tables 3 and 4). These associations were independent 
Table 2 Plasma levels of IL-10 and the risk of higher parasite densities after $24 \mathrm{~h}$ of treatment

\begin{tabular}{|c|c|c|c|c|c|c|c|c|c|}
\hline \multirow[b]{2}{*}{ IL-10 (pg/mL) } & \multicolumn{3}{|c|}{ Odds ratio ${ }^{\mathrm{a}}$} & \multicolumn{3}{|c|}{ Odds ratio ${ }^{b}$} & \multicolumn{3}{|c|}{ Odds ratio $^{c}$} \\
\hline & Odds & $95 \% \mathrm{CI}$ & $P$-value & Odds & $95 \% \mathrm{CI}$ & $P$-value & Odds & $95 \% \mathrm{CI}$ & $P$-value \\
\hline $0-185.99$ & $1 \cdot 00$ & Reference & & $1 \cdot 00$ & Reference & & $1 \cdot 00$ & Reference & \\
\hline $186-439.99$ & 1.05 & $(0 \cdot 34-3 \cdot 27)$ & 0.93 & 1.65 & $(0 \cdot 51-5 \cdot 33)$ & $0 \cdot 40$ & $2 \cdot 37$ & $(0 \cdot 61-9 \cdot 25)$ & $0 \cdot 21$ \\
\hline $434-746 \cdot 99$ & $2 \cdot 58$ & $(0 \cdot 83-8 \cdot 05)$ & $0 \cdot 10$ & $2 \cdot 93$ & $(0 \cdot 93-9 \cdot 23)$ & $0 \cdot 07$ & $3 \cdot 76$ & $(1 \cdot 00-14 \cdot 15)$ & 0.05 \\
\hline $747-1699 \cdot 99$ & $2 \cdot 95$ & $(0 \cdot 98-8 \cdot 86)$ & $0 \cdot 05$ & $2 \cdot 66$ & $(0 \cdot 88-8 \cdot 05)$ & $0 \cdot 08$ & $4 \cdot 44$ & $(1 \cdot 26-15 \cdot 66)$ & $0 \cdot 02$ \\
\hline $1700-15280$ & $29 \cdot 21$ & $(8 \cdot 07-105 \cdot 82)$ & 0.00 & $37 \cdot 78$ & $(9 \cdot 90-144 \cdot 20)$ & $0 \cdot 00$ & $69 \cdot 89$ & $(13 \cdot 47-362 \cdot 68)$ & $0 \cdot 00$ \\
\hline
\end{tabular}

The odds ratios estimate risk of higher parasite density and were generated using ordered polytomous logistic regression.

Adjustments were made for the variables: ${ }^{a}$ treatment, ${ }^{b}$ treatment and continuous log parasitaemia at time 0 , ${ }^{c}$ treatment, continuous log parasitaemia at time 0 , age, sex and temperature at time 0 .

Table 3 Plasma levels of IL-10 and the risk of higher parasite densities after $48 \mathrm{~h}$ of treatment

\begin{tabular}{|c|c|c|c|c|c|c|c|c|c|}
\hline \multirow[b]{2}{*}{ IL-10 (pg/ml) } & \multicolumn{3}{|c|}{ Odds ratio $^{a}$} & \multicolumn{3}{|c|}{ Odds ratio $^{\mathrm{b}}$} & \multicolumn{3}{|c|}{ Odds ratio $^{c}$} \\
\hline & Odds & $95 \% \mathrm{CI}$ & $P$-value & Odds & $95 \% \mathrm{CI}$ & $P$-value & Odds & $95 \% \mathrm{CI}$ & $P$-value \\
\hline $0-185 \cdot 99$ & $1 \cdot 00$ & Reference & & $1 \cdot 00$ & Reference & & $1 \cdot 00$ & Reference & \\
\hline $186-439 \cdot 99$ & $0 \cdot 84$ & $(0 \cdot 21-3 \cdot 29)$ & $0 \cdot 80$ & $1 \cdot 15$ & $(0 \cdot 28-4 \cdot 71)$ & $0 \cdot 85$ & $1 \cdot 12$ & $(0 \cdot 24-5 \cdot 16)$ & $0 \cdot 88$ \\
\hline $434-746 \cdot 99$ & $2 \cdot 51$ & $(0 \cdot 68-9 \cdot 27)$ & $0 \cdot 17$ & $2 \cdot 78$ & $(0 \cdot 75-10 \cdot 38)$ & $0 \cdot 13$ & $2 \cdot 92$ & $(0 \cdot 66-12 \cdot 94)$ & $0 \cdot 16$ \\
\hline $747-1699 \cdot 99$ & $4 \cdot 81$ & $(1 \cdot 34-17 \cdot 22)$ & $0 \cdot 02$ & $4 \cdot 36$ & $(1 \cdot 21-15 \cdot 71)$ & $0 \cdot 02$ & $4 \cdot 24$ & $(1 \cdot 05-17 \cdot 12)$ & $0 \cdot 04$ \\
\hline $1700-15280$ & $3 \cdot 15$ & $(0 \cdot 86-11 \cdot 54)$ & 0.08 & $2 \cdot 99$ & $(0 \cdot 81-11 \cdot 09)$ & $0 \cdot 10$ & $2 \cdot 50$ & $(0 \cdot 55-11 \cdot 42)$ & $0 \cdot 24$ \\
\hline
\end{tabular}

The odds ratios estimate risk of higher parasite density and were generated using ordered polytomous logistic regression.

Adjustments were made for the variables: ${ }^{a}$ treatment, ${ }^{b}$ treatment and continuous log parasitaemia at time 0 , ${ }^{c}$ treatment, continuous log parasitaemia at time 0 , age, sex and temperature at time 0 .

Table 4 Plasma levels of IL-10 and the risk of higher parasite densities after $72 \mathrm{~h}$ of treatment

\begin{tabular}{|c|c|c|c|c|c|c|c|c|c|}
\hline \multirow[b]{2}{*}{ IL-10 (pg $/ \mathrm{mL})$} & \multicolumn{3}{|c|}{ Odds ratio ${ }^{a}$} & \multicolumn{3}{|c|}{ Odds ratio ${ }^{b}$} & \multicolumn{3}{|c|}{ Odds ratio $^{c}$} \\
\hline & Odds & $95 \% \mathrm{CI}$ & $P$-value & Odds & $95 \% \mathrm{CI}$ & $P$-value & Odds & $95 \% \mathrm{CI}$ & $P$-value \\
\hline $0-185.99$ & $1 \cdot 00$ & Reference & & $1 \cdot 00$ & Reference & & $1 \cdot 00$ & Reference & \\
\hline $186-439 \cdot 99$ & $1 \cdot 34$ & $(0 \cdot 17-10 \cdot 51)$ & $0 \cdot 78$ & $1 \cdot 83$ & $(0 \cdot 28-4 \cdot 71)$ & $0 \cdot 58$ & $3 \cdot 85$ & $(0 \cdot 32-45 \cdot 69)$ & $0 \cdot 28$ \\
\hline $434-746 \cdot 99$ & $4 \cdot 43$ & $(0 \cdot 51-38 \cdot 38)$ & $0 \cdot 18$ & $5 \cdot 11$ & $(0 \cdot 75-10 \cdot 38)$ & $0 \cdot 14$ & $13 \cdot 72$ & $(0 \cdot 95-198 \cdot 78)$ & $0 \cdot 05$ \\
\hline $747-1699 \cdot 99$ & $10 \cdot 90$ & $(1 \cdot 67-71 \cdot 33)$ & $0 \cdot 01$ & $10 \cdot 01$ & $(1 \cdot 21-15 \cdot 71)$ & $0 \cdot 02$ & $16 \cdot 72$ & $(1 \cdot 68-165 \cdot 93)$ & $0 \cdot 02$ \\
\hline $1700-15280$ & $8 \cdot 38$ & $(1 \cdot 22-57 \cdot 46)$ & 0.03 & 8.35 & $(0 \cdot 81-11 \cdot 09)$ & 0.03 & $15 \cdot 64$ & $(1 \cdot 32-184 \cdot 89)$ & 0.03 \\
\hline
\end{tabular}

The odds ratios estimate risk of higher parasite density and were generated using ordered polytomous logistic regression.

Adjustments were made for the variables: ${ }^{a}$ treatment, ${ }^{b}$ treatment and continuous log parasitaemia at time 0 , ${ }^{c}$ treatment, continuous log parasitaemia at time 0 , age, sex and temperature at time 0 .

of all the potential confounding factors, even the finergrain measure of parasite density at $0 \mathrm{~h}$. IL-10 level was predictive of parasite densities in all treatment arms and there was no significant interaction of treatment strategy with IL-10 level $(P>0 \cdot 05)$ with regard to subsequent parasitaemia after adjustment for the main effects.
The median plasma level of IL-10 decreased during the treatment period, from the level at $0 \mathrm{~h}$ : 503 (lower and upper quartile: $(238-1479)) \mathrm{pg} / \mathrm{mL}$ to $198(55-483)$ and 124 (44238) $\mathrm{pg} / \mathrm{mL}$ at 48 and $72 \mathrm{~h}$, respectively. The median levels of IL-10 at 48 and $72 \mathrm{~h}$ were generally higher in the groups with the higher baseline levels of IL-10 (Figure 2). 

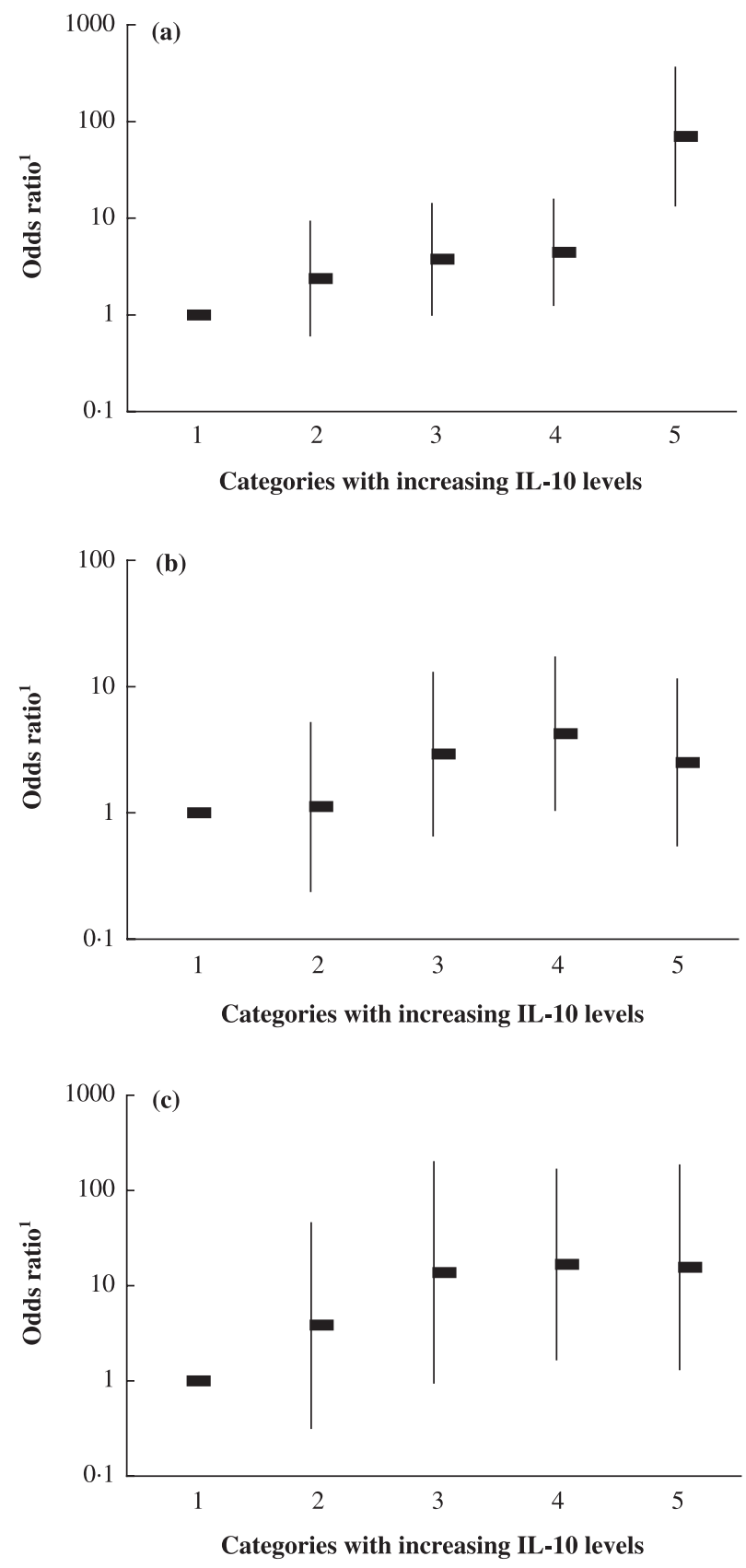

Figure 1 Odds ratios and 95\% confidence intervals for higher parasite densities at (a) 24, (b) 48 and (c) $72 \mathrm{~h}$ by IL-10 levels at $0 \mathrm{~h}$ were generated using ordered polytomous logistic regression. Simultaneous adjustment was made for continuous log parasitaemia at $0 \mathrm{~h}$, age, sex, treatment and temperature. Category boundaries for IL-10 levels are shown in Table 1.

To test the association of TNF- $\alpha$ with parasitaemia, the measure of TNF- $\alpha$ was divided into five ordinal categories, the first representing subjects with levels below the detectable threshold and the other four representing equally sized

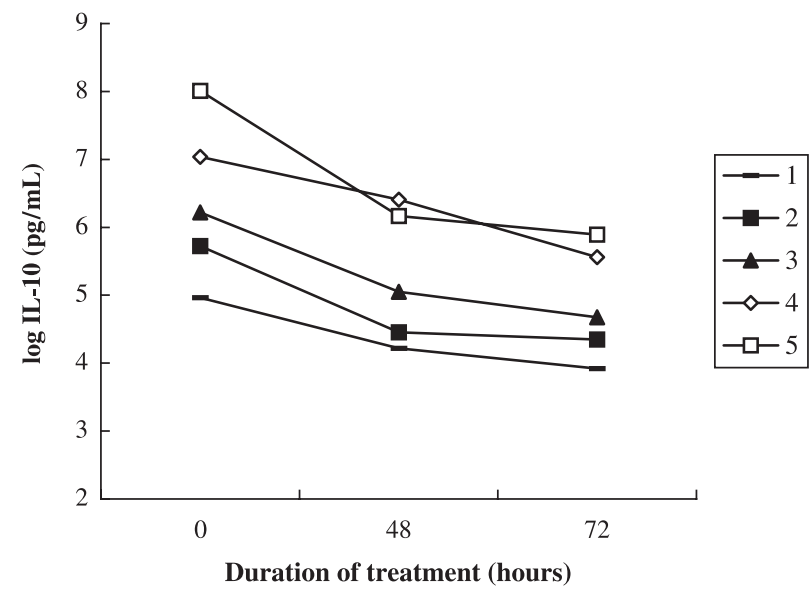

Figure 2 Medians of plasma IL-10 levels during treatment. The children were divided into five consecutive groups, with increasing baseline levels of IL-10. Category boundaries for IL-10 levels are shown in Table 1.

quarters of the detectable distribution. When compared by testing trends across the categories, there was no notable or statistically significant association between TNF- $\alpha$ concentration and parasitaemia (data not shown).

\section{DISCUSSION}

A positive association between serum IL-10 level and parasite density in symptomatic P. falciparum malaria (before start of treatment) has been described previously (13). The consequences of the presence of IL-10 for parasite killing are however, not known. We found associations between initial IL-10 levels and parasite densities during treatment, indicating that the IL-10 levels may play a role in the clearance of parasites during treatment. Since the IL-10 level is associated with the initial parasite burden, there is a risk that an association between IL-10 and parasite clearance may only reflect the situation that those with high parasitaemia at the start had more parasites throughout the treatment. Therefore we used a statistical model where the outcome was conditional on the initial parasitaemia (15). Such adjustment even enhanced the association between IL-10 level and the risk of having higher parasite density at $24 \mathrm{~h}$. This implies that IL-10 may be a better indicator of the parasiticidal efficacy during the first day of treatment than the initial parasitaemia. This was not an artefact due to a more precise measure of the distribution of IL-10 compared with initial parasitaemia in our modelling, since we used the most precise measure of the parasite distribution at day 0. By adjusting for temperature, treatment, age and sex we found that the associations were also independent of these potential confounding factors. 
Contrary to our results, Luty et al. found a negative association between parasite clearance time and in vitro induction of IL-10 production in malaria antigen stimulated PBMCs from Gabonese patients with acute $P$. falciparum infection (16). Their study investigated whether the donors responded with or without IL-10 production, indicating the need of $P$. falciparum antigen-specific cells to obtain faster clearance of parasites during treatment. In contrast, all our patients produced IL-10 and we focused on the relevance of the magnitude of production. The apparent difference in frequency of IL-10 detection is probably caused by the use of different methods.

One limitation of measuring cytokine levels in plasma or supernatants is that the bioactivity of the cytokine may be poorly correlated with the protein level. Additionally, cytokine detection after in vitro stimulation of cells in culture may reflect conditions that are not relevant to the in vivo situation. Theoretically, re-stimulation of cells already activated in vivo, may lead to in vitro apoptosis or anergy, which may underestimate the production of that cytokine in vivo. Few studies have compared serum and ex vivo induced cytokine production during infectious diseases but those generally show inconsistent results using these different techniques $(9,17-19)$. Other limitations in human studies are difficulties in measuring immune reactions in tissue or immune organs, apart from the peripheral blood. However, for blood stages of malaria the peripheral blood should be a relevant immune organ for studies of systemic regulatory molecules like IL-10. Consistent with this assumption, several studies have shown strong correlation between serum levels of IL-10 and clinical manifestations $(13,20)$. The levels of IL-10 detected here were within the range detected in similar studies: they were higher than some (10) and lower than others $(8,21)$.

The efficacy of anti-malarial drugs on parasite clearance depends on the sensitivity of the parasite, the drug levels over time and the immune defence (22). In our study the patients were treated with four different drug regimens with different parasite clearance rates (14). Type of treatment did not affect our results, since IL-10 was predictive of parasite clearance in all treatment arms and there was no interaction between IL-10 level and treatment arm. Our study thus identified a general association between IL-10 level and reduced parasite clearance irrespective of treatment. This does not necessarily imply a similar negative effect on parasite clearance in untreated malaria.

The drop in IL-10 levels over the study period implies that the IL-10 production is affected by the treatment, the reduction in parasite load or other disease causing factors. The cause-effect relationship between these variables could not be identified with our model but would be interesting to address in future studies.

Since the mechanism (s) of parasite killing has not been fully described, we can only speculate how IL-10 may influ- ence parasite clearance. IL-10 is an important immune modulating factor executing anti-inflammatory activities by inhibiting activation of antigen-presenting cells (APC), reducing their ability to induce $\mathrm{T}$ cell responses (23). IL-10 inhibits APC production of cytokines and effector molecules like $\mathrm{NO}^{-}$(23). Stimulation of T cells in the presence of IL-10 is also thought to promote induction of regulatory $\mathrm{T}$ cells, which become tolerant or unresponsive to the stimulating antigen $(24,25)$. The inhibitory effects seen for IL-10 on parasite killing could operate at any of these levels. $\mathrm{NO}^{-}$and reactive oxygen intermediates have been proposed as possible effector molecules in malaria parasite killing $(4,26,27)$ and data suggest an association between increased levels of these molecules and shorter parasite clearance time $(22,28)$. High IL-10 levels might thus aggravate the disease by downregulating the production of these molecules directly or via down-regulation of pro-inflammatory cytokines. In support of this, other reports show lower levels of plasma IL-12 or $\mathrm{NO}^{-}$in combination with higher IL-10 and TNF levels in more severe forms of malaria $(12,13)$. Studying ratios between pro- and anti-inflammatory cytokines for the prognostic of parasite killing might add more information of what cytokine profiles are beneficial or detrimental (29). In this way it was identified that hyperparasitaemia in children was associated with higher ratios of IL-10 : TNF plasma levels (11). We could not study ratios between IL-10 and TNF- $\alpha$ here because of insufficiently sensitivity of the TNF- $\alpha$ detection, but this would be worth trying in future studies. Hence, we found no univeriate association between TNF- $\alpha$ and parasitaemia, nor between TNF- $\alpha$ and any of the parasite categories.

The parasite might 'deliberately' enhance the IL-10 production in order to interfere with the balance between proand anti-inflammatory immune reactions to escape effective parasite killing. There is in vitro evidence that falciparuminfected erythrocytes increase the secretion of IL-10 and reduce the secretion of IL-12 during maturation of dendritic cells $(30,31)$. These effects on DC were similar to what was found when the cells were exposed to apoptotic cells or ligation of CD36 and/or CD51. Such mechanisms might be overcome after repeated infections, since neither high levels of IL-10 nor particular pro-inflammatory responses are found in children in endemic areas with significant numbers of parasites but without clinical symptoms (21).

Differences in the magnitude of IL-10 production may reflect differences in host characteristics, including genetic differences, semi-immunity, co-infections or nutritional status and possibly differences in parasite strains. In any event, our data suggest that higher IL-10 levels are associated with poorer subsequent parasite clearance. Thus, IL-10 levels may represent a useful prognostic marker in identifying patients who are more susceptible to slower parasite clearance. 


\section{ACKNOWLEDGEMENTS}

We would like to thank the children, their families and the staff at Kibaha Hospital for their participation in this study. We thank Donath Tarimo, Fredrick Kalokola, the late Jeremiah Masunga and Anette Sundstedt for clinical and laboratory assistance in the hospital. The work was supported by the Swedish International Development Co-operation Agency (Sarec), the Swedish Medical Research Council and Bergvall's Foundation.

\section{REFERENCES}

1 Stevenson MM, Tam MF, Wolf SF \& Sher A. IL-12-induced protection against blood-stage Plasmodium chabaudi AS requires IFN-gamma and TNF-alpha and occurs via a nitric oxidedependent mechanism. J Immunol 1995; 155: 2545-2556.

2 Shear HL, Srinivasan R, Nolan T \& Ng C. Role of IFN-gamma in lethal and nonlethal malaria in susceptible and resistant murine hosts. J Immunol 1989; 143: 2038-2044.

3 De Souza JB, Williamson KH, Otani T \& Playfair JH. Early gamma interferon responses in lethal and nonlethal murine blood-stage malaria. Infect Immun 1997; 65: 1593-1598.

4 Rockett KA, Awburn MM, Cowden WB \& Clark IA. Killing of Plasmodium falciparum in vitro by nitric oxide derivatives. Infect Immun 1991; 59: 3280-3283.

5 Jacobs P, Radzioch D \& Stevenson MM. A Th1-associated increase in tumor necrosis factor alpha expression in the spleen correlates with resistance to blood-stage malaria in mice. Infect Immun 1996; 64: 535-541.

6 Waki S, Uehara S, Kanbe K, Ono K, Suzuki M \& Nariuchi H. The role of $\mathrm{T}$ cells in pathogenesis and protective immunity to murine malaria. Immunology 1992; 75: 646-651.

7 Kremsner PG, Neifer S, Chaves MF, Rudolph R \& Bienzle U. Interferon-gamma induced lethality in the late phase of Plasmodium vinckei malaria despite effective parasite clearance by chloroquine. Eur J Immunol 1992; 22: 2873-2878.

8 Kurtzhals JA, Adabayeri V, Goka BQ, et al. Low plasma concentrations of interleukin 10 in severe malarial anaemia compared with cerebral and uncomplicated malaria. Lancet 1998; 351: 1768-1772.

9 Mordmuller BG, Metzger WG, Juillard P, et al. Tumor necrosis factor in Plasmodium falciparum malaria: high plasma level is associated with fever, but high production capacity is associated with rapid fever clearance. Eur Cytokine Netw 1997; 8: 29-35.

10 Othoro C, Lal AA, Nahlen B, Koech D, Orago AS \& Udhayakumar V. A low interleukin-10 tumor necrosis factoralpha ratio is associated with malaria anemia in children residing in a holoendemic malaria region in western Kenya. $J$ Infect Dis 1999; 179: 279-282.

11 May J, Lell B, Luty AJ, Meyer CG \& Kremsner PG. Plasma interleukin-10: Tumor necrosis factor (TNF)-alpha ratio is associated with TNF promoter variants and predicts malarial complications. J Infect Dis 2000; 182: 1570-1573.

12 Anstey NM, Weinberg JB, Hassanali MY, et al. Nitric oxide in Tanzanian children with malaria: inverse relationship between malaria severity and nitric oxide production/nitric oxide synthase type 2 expression. J Exp Med 1996; 184: 557-567.

13 Luty AJ, Perkins DJ, Lell B, et al. Low interleukin-12 activity in severe Plasmodium falciparum malaria. Infect Immun 2000; 68: $3909-3915$.
14 Hugosson E, Tarimo D, Troye-Blomberg M, Montgomery SM, Premji Z \& Bjorkman A. Antipyretic, parasitologic, and immunologic effects of combining sulfadoxine/pyrimethamine with chloroquine or paracetamol for treating uncomplicated Plasmodium falciparum malaria. Am J Trop Med Hyg 2003; 69: 366-371.

15 Plewis I. Analysing Change ed. London, Wiley, 1985.

16 Luty AJ, Lell B, Schmidt-Ott R, et al. Parasite antigen-specific interleukin-10 and antibody responses predict accelerated parasite clearance in Plasmodium falciparum malaria. Eur Cytokine Netw 1998; 9: 639-646.

17 Jason J, Archibald LK, Nwanyanwu OC, et al. Comparison of serum and cell-specific cytokines in humans. Clin Diagn Laboratory Immunol 2001; 8: 1097-1103.

18 Walker D, Jason J, Wallace K, et al. Spontaneous cytokine production and its effect on induced production. Clin Diagn Laboratory Immunol 2002; 9: 1049-1056.

19 Vankayalapati R, Wizel B, Weis SE, et al. Serum cytokine concentrations do not parallel Mycobacterium tuberculosis-induced cytokine production in patients with tuberculosis. Clin Infect Dis 2003; 36: 24-28.

20 Day NP, Hien TT, Schollaardt T, et al. The prognostic and pathophysiologic role of pro- and anti-inflammatory cytokines in severe malaria. J Infect Dis 1999; 180: 1288-1297.

21 Jakobsen PH, McKay V, N'Jie R, et al. Soluble products of inflammatory reactions are not induced in children with asymptomatic Plasmodium falciparum infections. Clin Exp Immunol 1996; 105: 69-73.

22 Greve B, Lehman LG, Lell B, Luckner D, Schmidt-Ott R \& Kremsner PG. High oxygen radical production is associated with fast parasite clearance in children with Plasmodium falciparum malaria. J Infect Dis 1999; 179: 1584-1586.

23 Moore KW, de Waal Malefyt R, Coffman RL \& O'Garra A. Interleukin-10 and the interleukin-10 receptor. Аnпи Rev Immunol 2001; 19: 683-765.

24 Groux H, O'Garra A, Bigler M, et al. A CD4 ${ }^{+}$T-cell subset inhibits antigen-specific T-cell responses and prevents colitis. Nature 1997; 389: 737-742.

25 Tanchot C, Guillaume S, Delon J, et al. Modifications of CD8 ${ }^{+}$ $\mathrm{T}$ cell function during in vivo memory or tolerance induction. Immunity 1998; 8: 581-590.

26 Clark IA \& Hunt NH. Evidence for reactive oxygen intermediates causing hemolysis and parasite death in malaria. Infect Immun 1983; 39: 1-6.

27 Thumwood CM, Hunt NH, Cowden WB \& Clark IA. Antioxidants can prevent cerebral malaria in Plasmodium berghei-infected mice. Evidence for reactive oxygen intermediates causing haemolysis and parasite death in malaria. Br J Exp Pathol 1989; 70: 293-303.

28 Kremsner PG, Winkler S, Wildling E, et al. High plasma levels of nitrogen oxides are associated with severe disease and correlate with rapid parasitological and clinical cure in Plasmodium falciparum malaria. Trans $R$ Soc Trop Med Hyg 1996; 90: 44-47.

29 Dodoo D, Omer FM, Todd J, Akanmori BD, Koram KA \& Riley EM. Absolute levels and ratios of pro-inflammatory and anti-inflammatory cytokine production in vitro predict clinical immunity to Plasmodium falciparum malaria. J Infect Dis 2002; 185: 971-979.

30 Urban BC, Ferguson DJ, Pain A, et al. Plasmodium falciparuminfected erythrocytes modulate the maturation of dendritic cells. Nature 1999; 400: 73-77.

31 Urban BC, Willcox N \& Roberts DJ. A role for CD36 in the regulation of dendritic cell function. Proc Natl Acad Sci USA 2001; 98: 8750-8755. 